\title{
Telemedicine-equipped android interface-based heart rate monitoring
}

\author{
Hanifah Rahmi Fajrin', Bayu Satrio Adi ${ }^{2}$, Heri Purwoko ${ }^{3}$, Irma Permata Sari ${ }^{4}$
}

${ }^{1,2}$ Department of Medical Electronics Technology, Universitas Muhammadiyah Yogyakarta, Indonesia

${ }^{3}$ Wirosaban Public Hospital, Yogyakarta, Indonesia

${ }^{4}$ Department of System and Information Technology, Jakarta State University, Indonesia

\section{Article Info}

Article history:

Received Dec 7, 2019

Revised Mar 9, 2020

Accepted May 5, 2020

\section{Keywords:}

Bluetooth

Heart Rate

Telemedicine

Android

\begin{abstract}
This research aimed to design a device that can monitor heart rate and help nurses or doctors when they need to monitor and retrieve data of patients. By utilizing Android as a displayer makes it easier for nurses to minimize data retrieval time. The principle of the tool is to record the heart rate data received by the ear clip sensor to be processed by the Atmega328 microcontroller, then displayed on the Oled LCD and sent to Android phones via HC-05 Bluetooth for display. If the heart rate data is beyond the normal range, the Android application will post a notification in the form of an SMS to the recipient's cellphone. In testing the tool, it uses a comparison device (pulse oximetry) to determine its accuracy. Based on the testing, the heart rate monitoring device had a small error value of $0.32 \%$ and had the most substantial error value of $0.81 \%$. The application of the monitoring system in android data can be sent well at a maximum distance of 13 meters, as well as the implementation of telemedicine in the form of a warning (SMS) can work properly.
\end{abstract}

This is an open access article under the CC BY-SA license.

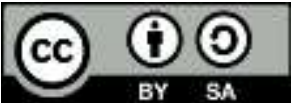

\section{Corresponding Author:}

Hanifah Rahmi Fajrin

Department of Medical Electronics Technology

Universitas Muhammadiyah Yogyakarta

Jalan Brawijaya, Taman Tirto, Kasihan, Bantul, Indonesia 55183.

Email: hanifah.fajrin@ vokasi.umy.ac.id

\section{INTRODUCTION}

Heart rate is a beat released by the heart due to blood flows through the heart, and one of the crucial parameters and vital signs to be monitored routinely by paramedics [1]. Also, the heart rate is used by paramedics to find out the physical condition and mental state of a person [2]. If a person's heart rate is abnormal, then further efforts need to be made to avoid undesirable things [3]. Any person can experience heart problems or suffer from heart disease [4].

Based on data from the World Heart Federation, deaths caused by heart disease range from 17.1 million people (19\% of total deaths) per year [5]. This number is four times the population of Singapore. In Indonesia, based on the records of the Indonesian Heart Foundation, the prevalence is $7-12 \%$ per year. That is, at least 16.8 million out of 240 million people in Indonesia suffer from heart disease. Of this number, those in $30-50$ years old (productive age) are $50 \%$ of the total number [6].

There are still many people who do not realize that they suffer heart disease and eventually find out after being severely affected [7]. The lack of awareness of the public about the importance of the heart as the primary life support makes the death rate caused by heart disease increases every year [8]. Although coupled with medical equipment to monitor or check the heart rate condition, the stethoscope is less effective for 
nurses and doctors [9], because it still takes time to reach the patient's room when monitoring and retrieving the patient's heart rate data. When the patient's condition suddenly worsens, there will be time wasted looking for or calling on nurses and doctors [1,7]. So we need a smart health device that is able to immediately display patient's data without having to go to the patient's room [10]. With the existence of these devices/tools, nurses and doctors can shorten the time in taking data, monitoring patients, or taking immediate action in the event undesirable things on the patient's heart [11, 12]. Based on data from Asymco analyst - Horace Dediu, Indonesia is now the fifth-ranked country with the most smartphone users in the world, with 1 billion users [13].

In previous research [14] a smartphone accessory was designed to determine the heart rate, especially for cardiac patients who need to monitor their heart rate. It became an essential indicator for prognosis and diagnosis to share with their physician anytime to seek medical advice when needed. The first step is the explanation of how to extract the ECG signal from the patient. After that, the presentation about the methods to filter the signal, to calculate the heart rate, and the last is to send the heart rate to the patient's smartphone. There are three sections to clarify the function of each block in building the smartphone accessory. A design for a mobile heart rate monitor device includes both software and hardware that can provide patients with a portable heart rate monitor in the form of a smartphone accessory connected via USB to the phone. It continuously tracks the medical condition and alerts of any possible life-threatening heart complications, in addition to share the resulted heart rate with their physician by sending an SMS to seek medical help and supervision with a press of a single button. However, the device only provides connection via USB, so it is not portable.

Hasmah Mansor et al. [15] designed a health monitoring system equipped with heart rate and body temperature wireless sensors. The main components involved in this project were pulse sensor, microcontroller (Arduino with Ethernet shield), and wireless communication device (Xbee). Results showed that the real-time heart rate reading successfully monitored locally (at home) and remotely (at doctor's computer). The performance and efficiency of the device can be further improved in future especially in terms of connection in other platforms besides computer. Possibly, the heart rate sensor can be designed to be worn at the ear lobe so that it will not interrupt patient's activities.

Similar to the previous one, [16] the researcher developed a working prototype of an assistive wireless device for bedridden patients. The device continuously monitors the heart rate of the patient. The device communicates with a mobile in which a customizable application will enable the alert mechanism. The communication between the device and the mobile is via GSM Module. The major parts of this project are Heart Beat Sensor, Arduino Uno, and LCD \& GSM Module. In this project, the highest error value reached $6.49 \%$ which is high for diagnostic devices. Less sensitive sensor readings may affect it because the sensor is fitted at the fingertips.

The description of the problem stated hereinabove encourages the author to design a device that can be used in a hospital to help nurses or doctors in monitoring and retrieving data on patients' heart rate conditions by using android [17] as a data displayer and health information technology (Telemedicine) by sending short messages or texting information data on the status of the patient when reaching abnormal heart rate range to the doctor or nurse [18-20]. The sensor is an ear clip sensor which is more effective and accurate [21].

\section{RESEARCH METHOD}

Several stages of work include hardware design, software design, testing device/tool, and data collection to achieve the expected purpose.

\subsection{Block diagram}

Based on Figure 1, it can be seen that the patient whose heartbeats are monitored, his earlobe is clamped with the ear clip sensor. Inside the sensor there is an infrared light that will illuminate the earlobe and there is also a photodiode sensitive to light intensity [22]. Every time blood flows, there is a difference in light intensity, which will then be received by the photodiode. The analog signal from the photodiode is processed in a signal conditioning circuit, which consists of a filter where the results of signal capture from the sensor are filtered to reduce noise from the signal [23]. Then the analog data are amplified by a signal conditioning circuit because the received signal is minimal. The signal that has been filtered and amplified is processed in the microcontroller to calculate the patient's BPM value. The output signal enters the ADC on the microcontroller. The microcontroller reads the time interval between signals in every ten pulses of heart blood flow. The obtained data will be converted to a BPM value and displayed on the LCD. The analog signal output from the signal conditioning amplifying is also compared to the reference in the comparator circuit [24]. The output of the comparator is in the form of a high or low signal and triggers the transistor as 
an indicator of a slow heart rate. The BPM value is then transferred to Bluetooth to be sent to the Android application [25]. If the BPM value is below 60 or above 100, the Android app will send an SMS to the operator to find out the patient's condition and provide immediate medical action to the patient [26].

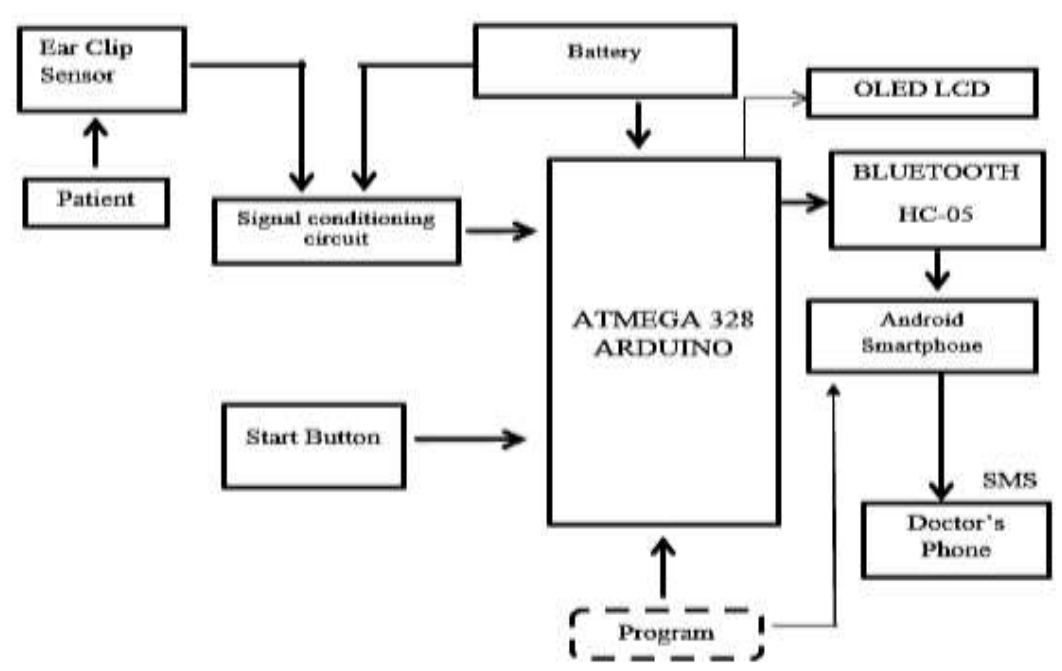

Figure 1. Block diagram

\subsection{Hardware design}

At the hardware design stage, making a circuit block consists of making an Ear Clip sensor circuit block, signal conditioning circuit, and a microcontroller circuit of the ATMega328p system.

\subsubsection{Ear clip sensor circuit}

The Circuit of Ear Clip Sensor is in Figure 2. This Ear Clip sensor circuit consists of two resistors with a value of $220 \mathrm{ohms}$ for the infrared led and 100k ohm for the photodiode [27]. This series of Ear Clip Sensor function is to calculate the number of heartbeats in units of BPM (beat per minute) when infrared emits light passes through the earlobe, and the photodiode captures the light. Because of the influence of blood flow, signals arise $[28,29]$.

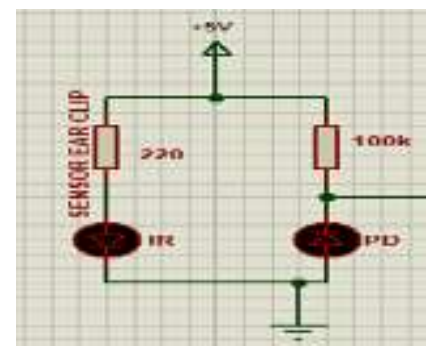

Figure 2. Ear clip sensor circuit

\subsubsection{Signal conditioning circuit}

Component specifications used in the signal conditioning circuit is in Figure 3. It consists of:

a. High pass filter (HPF), non-inverting amplifier, and comparator.

b. $100 \mathrm{k} \mathrm{ohm}$ variable resistor for comparator reference controllers.

c. There is an input signal indicator, namely the red led.

d. LM 35, NE $555 \mathrm{ICs}$, and 2n222 transistor.

This signal conditioning circuit receives a signal from the ear clip sensor which is then filtered to reduce noise and will be amplified using the LM358 IC which has two op-amps [30], where the first op-amp is for non-inverting amplifier [31], and the second op-amp is to buffer so that the resulting amplifying is 
stable. The amplified voltage is compared by a comparator (LM393 IC) where the reference voltage of the comparator is $+5 \mathrm{~V}$. The output of the comparator will trigger the $2 \mathrm{n} 222$ transistor where in turn will become an indicator that the signal from the sensor has been received and then give output to forward to the ATMega 328 microcontroller system.

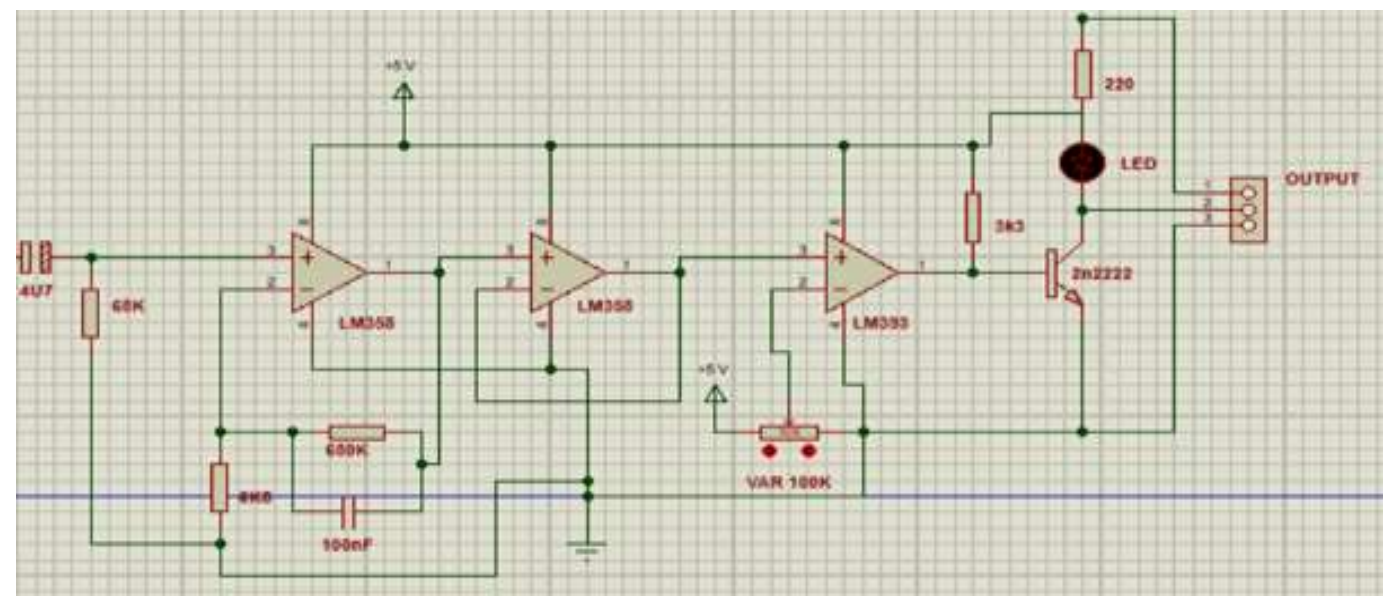

Figure 3. Signal conditioning circuit

\subsubsection{ATMega328p microcontroller}

Figure 4 shows that the component specifications used in the Microcontroller of the ATMega328p are:

a. ATMega328p.

b. Crystal.

c. Operating voltage of $+5 \mathrm{~V}$, and GND.

d. Push button resistor $10 \mathrm{k} \Omega, 4 \mathrm{k} 7 \Omega$, and $100 \mathrm{nF}, 22 \mathrm{pF}$ capacitor.

ATMega328p acts as a controller of the system as a data displayer and data processor, as data sender from tool to the android application. The microcontroller consists of ATMega328p, crystal, and reset button [32].

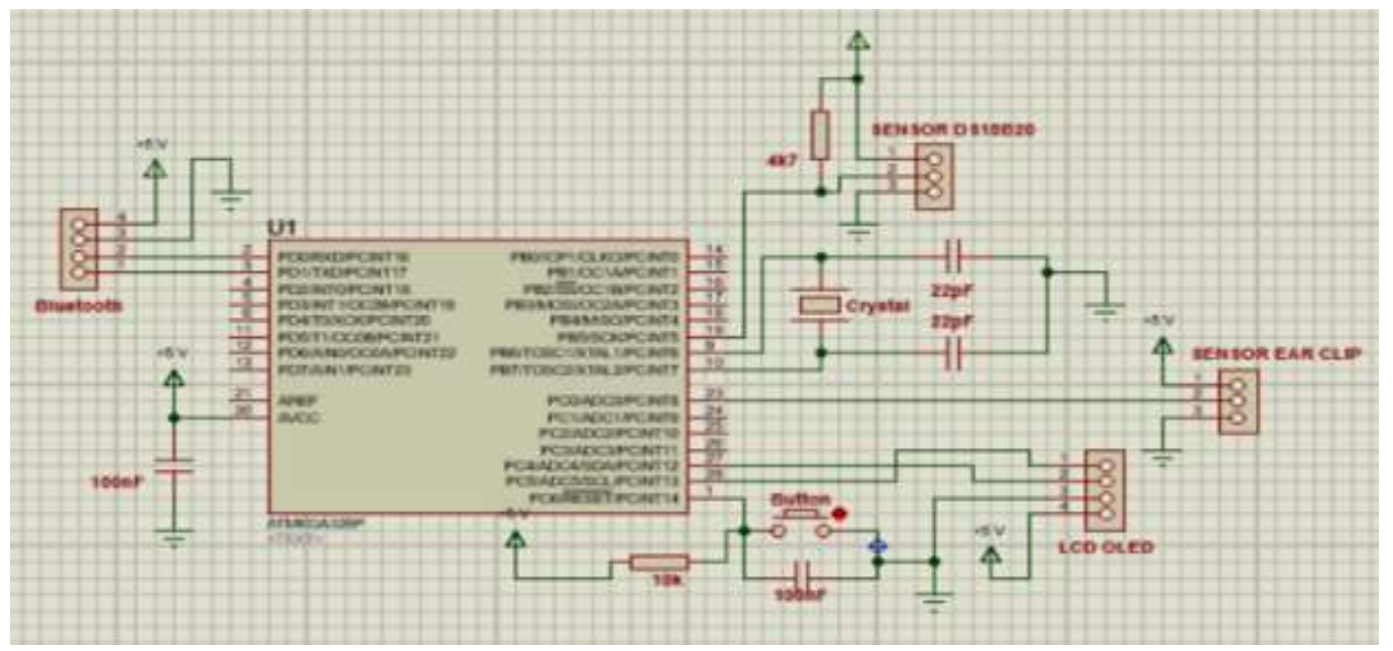

Figure 4. ATMega328p microcontroller

\subsection{Software design}

The software is designed to control the workings of a telemedicine-equipped android interactionbased heart rate monitoring tools. The software needed for making the device is Arduino software and MIT App Inventor. 


\subsubsection{Ardunio software}

Arduino software platform can be seen in Figure 5. This Arduino software is used as access to the hardware that has been made [33]. All the desired commands can be embedded in the controller system later, such as the command data, to forward the displayed data to Android [5].

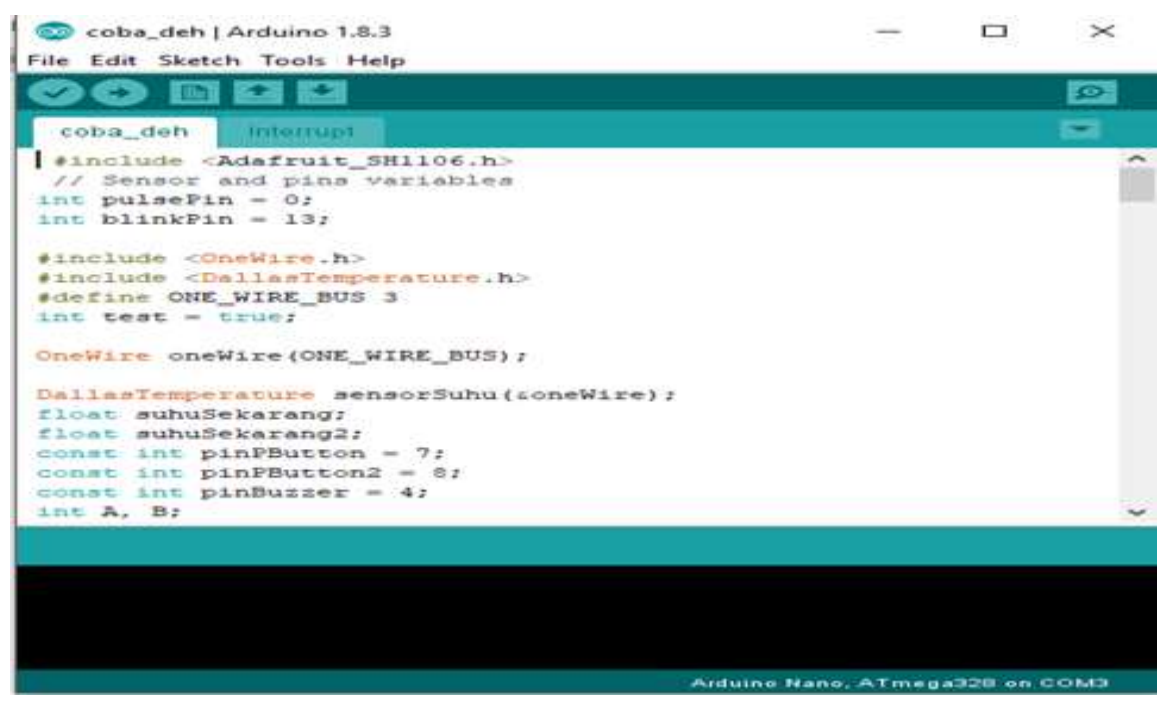

Figure 5. Arduino software

\subsubsection{MIT app inventor}

Figure 6 is a platform of MIT App Inventor. It is a website that provides facilities to create an android application [34]. The designed application can receive data, save data and send SMS to the predetermined number.

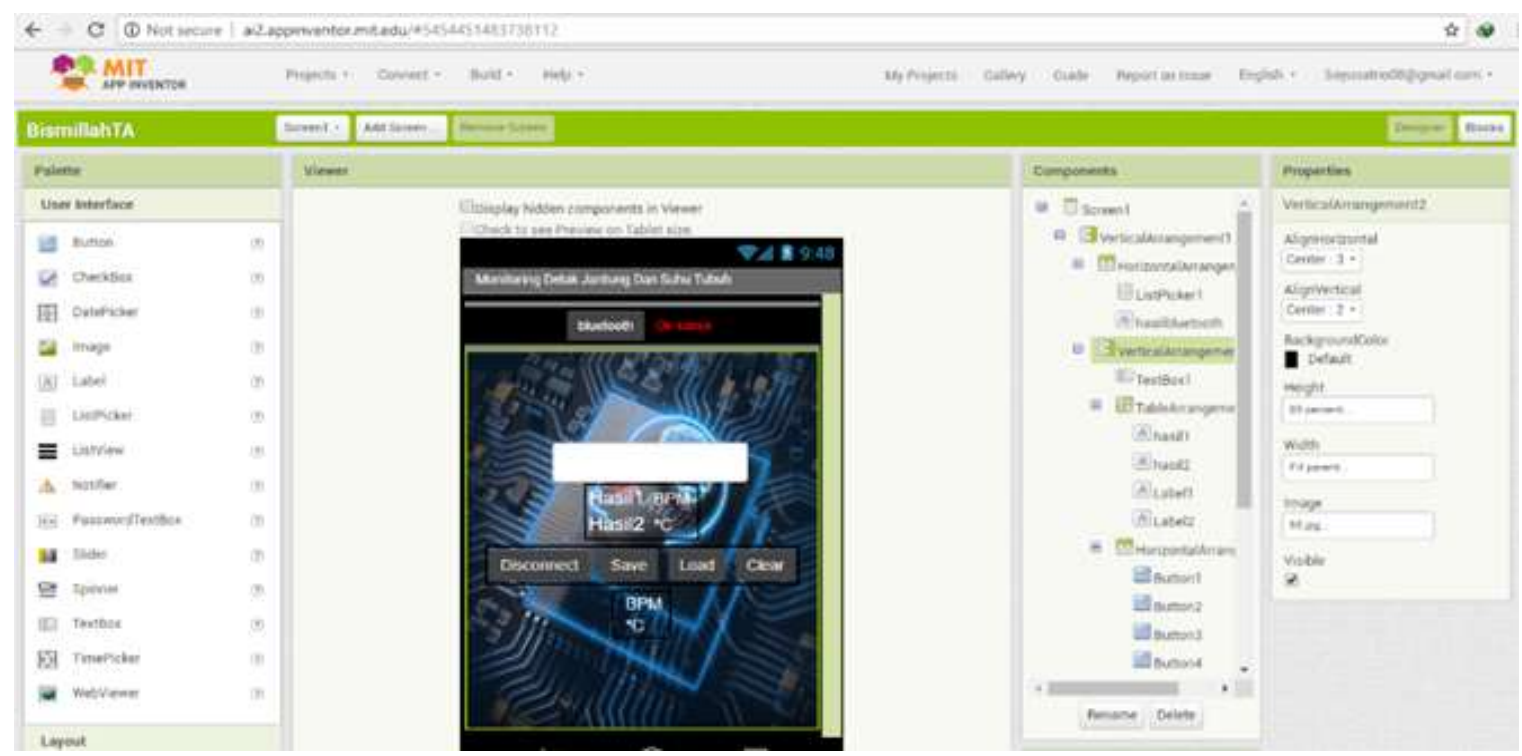

Figure 6. MIT app inventor

\section{RESULTS AND DISCUSSION}

In this study, the authors conducted a tool test by measuring heart rate (BPM) with pulse oximetry, measuring the maximum distance of sending data from the hardware/tool to android, and sending messages (SMS) to the number entered. 


\subsection{Results of measurement on respondents}

The following data in Table 1 is the heart rate data obtained from the measurement of 10 respondents in three different times. In the process of collecting heart rate data, a comparator (Pulse Oximeter) was mounted on the finger, and the tool was mounted on the earlobe. Then respondents were then conditioned to relax.

Based on the results of measurements and comparisons using pulse oximeter [17], different results were obtained with a different value in each respondent. The smallest error value was $0.32 \%$, and the highest was $0.81 \%$. The error value existed because there were other factors such as the location of the sensor module with different comparisons. Besides, the measurement time on the tool was slightly longer than the comparator that measured continuously.

\subsection{Results of distance measurement}

The distance measurement between tool and android was conducted with the existence and nonexistence of obstacles. Based on the results of distance measurement between the tool and android application in Table 2, the data could be sent at a maximum distance of 13 meters. At the distance of 14-15 meters, the connection started to be unstable and disturbed. The transmitted data was difficult to read by the android application. At the range of 16-20 meters and further, data could not be read, and the connection between the module's Bluetooth and smartphone's Bluetooth had been disconnected [25], as seen in Figure 7.

Table 1. The results of measurement on respondents

\begin{tabular}{|c|c|c|c|c|c|}
\hline \multirow[t]{2}{*}{ Respondent } & \multirow[t]{2}{*}{ Device } & \multicolumn{3}{|c|}{ Measurement (BPM) } & \multirow[t]{2}{*}{ Error (\%) } \\
\hline & & 1 & 2 & 3 & \\
\hline \multirow[t]{2}{*}{1} & Pulse Oximeter & 84 & 85 & 86 & 0.4 \\
\hline & Tool & 82 & 85 & 87 & \\
\hline \multirow[t]{2}{*}{2} & Pulse Oximeter & 103 & 104 & 105 & 0.32 \\
\hline & Tool & 102 & 103 & 106 & \\
\hline \multirow[t]{2}{*}{3} & Pulse Oximeter & 86 & 83 & 83 & 0.79 \\
\hline & Tool & 85 & 84 & 81 & \\
\hline \multirow[t]{2}{*}{4} & Pulse Oximeter & 83 & 82 & 82 & 0.81 \\
\hline & Tool & 82 & 81 & 82 & \\
\hline \multirow[t]{2}{*}{5} & Pulse Oximeter & 90 & 92 & 93 & 0.37 \\
\hline & Tool & 90 & 94 & 92 & \\
\hline \multirow[t]{2}{*}{6} & Pulse Oximeter & 94 & 94 & 95 & 0.34 \\
\hline & Tool & 93 & 93 & 96 & \\
\hline \multirow[t]{2}{*}{7} & Pulse Oximeter & 90 & 90 & 91 & 0.34 \\
\hline & Tool & 91 & 89 & 93 & \\
\hline \multirow[t]{2}{*}{8} & Pulse Oximeter & 92 & 91 & 92 & 0.72 \\
\hline & Tool & 92 & 91 & 90 & \\
\hline \multirow[t]{2}{*}{9} & Pulse Oximeter & 97 & 96 & 98 & 0.69 \\
\hline & Tool & 97 & 95 & 97 & \\
\hline \multirow[t]{2}{*}{10} & Pulse Oximeter & 78 & 76 & 77 & 0.44 \\
\hline & Tool & 77 & 75 & 78 & \\
\hline
\end{tabular}

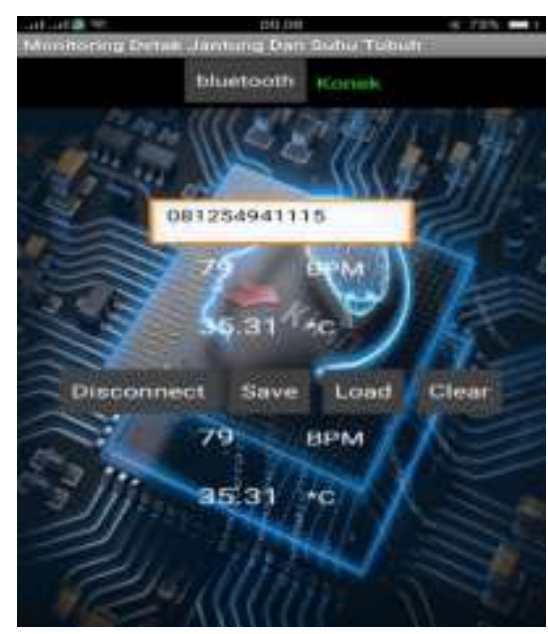

Figure 7. Data received by android 
Table 2. Distance measurement

\begin{tabular}{cll}
\hline Distance $(\mathrm{m})$ & Data & Bluetooth Connection \\
\hline 1 & Sent & Stable \\
2 & Sent & Stable \\
3 & Sent & Stable \\
4 & Sent & Stable \\
5 & Sent & Stable \\
6 & Sent & Stable \\
7 & Sent & Stable \\
8 & Sent & Stable \\
9 & Sent & Stable \\
10 & Sent & Stable \\
11 & Sent & Stable \\
12 & Sent & Stable \\
13 & Sent & Stable \\
14 & Sent & Unstable \\
15 & Sent & Unstable \\
16 & Not Sent & Disconnected \\
17 & Not Sent & Disconnected \\
18 & Not Sent & Disconnected \\
19 & Not Sent & Disconnected \\
20 & Not Sent & Disconnected \\
\hline
\end{tabular}

\subsection{The results of message (SMS) delivery monitoring}

The results of this monitoring were conducted by waiting for the condition of the heart rate to be abnormal or exceeds the range of 60-100. Based on the results of data transmission (SMS) monitoring in Table 3, the results obtained were as desired. If the detected data were less than or more than the standard BPM value $(<60$ or $>100)$, the application would display a warning sign and send an SMS to the doctor/nurse/operator that the BPM value of the patient/respondent was not good or abnormal. Then if the value on the data were detected normally (60-100 BPM), the application would not display a warning sign nor send an SMS to the doctor/nurse/operator, as illustrated in Figure 8.

Table 3. Message (SMS) monitoring

\begin{tabular}{ccc}
\hline BPM Data & SMS Status & SMS Description \\
\hline$<60$ BPM & Sent & Bad condition \\
$60-100$ BPM & Not Sent & - \\
$<100$ BPM & Sent & Bad condition \\
\hline
\end{tabular}
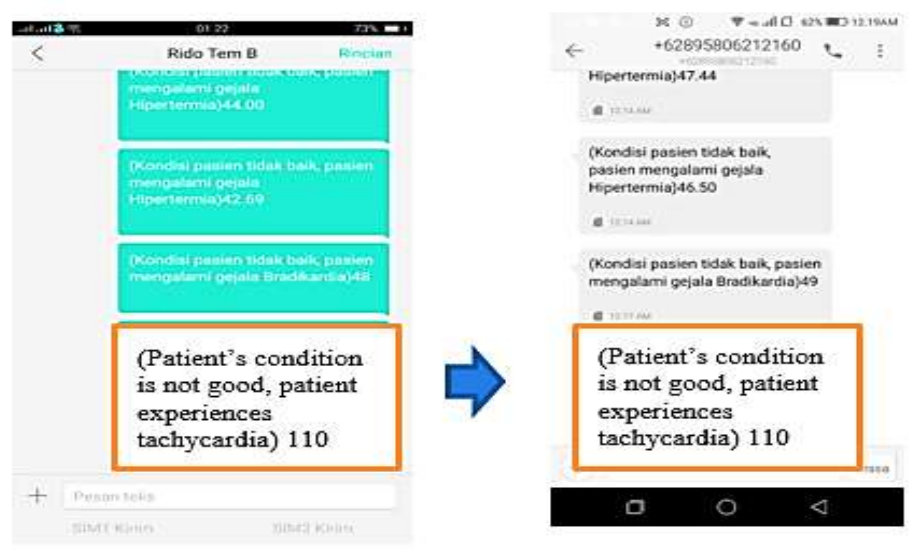

Figure 8. Patient's data sent

\section{CONCLUSION}

After conducting the process of creation and planning literature study, device testing, as well as data collection, the heart rate monitoring device based on android could work well. The obtained error value after performing measurement and calculation were the lowest of $0.23 \%$ and the highest of $0.81 \%$. The android 
application connected to the tool also worked well to display data at a maximum distance of 13 meters. The app also saved data as well as send SMS to doctor/nurse/operator when the heartbeat condition is $<60$ or $>100$ BPM.

\section{REFERENCES}

[1] J. K. Abed and H. M. Abed, "Smart monitor of pacemaker patient by using iot cloud in real time," Indonesian Journal of Electrical Engineering and Computer Science, vol. 18, no. 1, pp. 158-166, 2020.

[2] B. F. Wu, et al, "Remote HeartRate Measurement based on Signal Feature Detection in Time Domain," Proc. 2019 Int. Conf. Syst. Sci. Eng. ICSSE 2019, pp. 88-93, 2019.

[3] K. Bhagchandani and D. Peter Augustine, "IoT based heart monitoring and alerting system with cloud computing and managing the traffic for an ambulance in India," International Journal of Electrical and Computer Engineering (IJECE), vol. 9, no. 6, pp. 5068-5074, 2019.

[4] A. L. Valor, et al, "HeartSaver: A heart rate monitoring system with SMS notification," Proc. - 2016 IEEE Conf. Syst. Process Control, ICSPC 2016, no. December, pp. 1-6, 2017.

[5] S. Hadiyoso, D. R. Mardiyah, D. N. Ramadan, and A. Ibrahim, "Implementation of electronic stethoscope for online remote monitoring with mobile application," Bulletin of Electrical Engineering and Informatics, vol. 9, no. 4, pp. 1595-1603, 2020.

[6] C. Chow, et all, "Reducing the burden of Cardiovascular Disease in Indonesia," The George Institute for Global Health, missenden new south wales: the george institute for global health, 2017.

[7] E. Akanksha, "Framework for propagating stress control message using heartbeat based IoT remote monitoring analytics," International Journal of Electrical and Computer Engineering, vol. 10, no. 5, pp. 4615-4622, 2020.

[8] J. A. Dawson, G. M. Schmölzer, and J. Wyllie, "Monitoring heart rate in the delivery room," Semin. Fetal Neonatal Med., vol. 23, no. 5, pp. 327-332, 2018.

[9] H. K. Ra, J. Ahn, H. J. Yoon, J. Ko, and S. H. Son, “Accurately Measuring Heartrate Using Smart Watch,” Proc. 2016 IEEE 22nd Int. Conf. Embed. Real-Time Comput. Syst. Appl. RTCSA 2016, vol. 56, no. 24, p. 100, 2016.

[10] H. R. Fajrin, M. R. Ilahi, B. S. Handoko, and I. P. Sari, "Body temperature monitoring based on telemedicine," $J$. Phys. Conf. Ser., vol. 1381, no. 1, 2019.

[11] M. Peng, T. Wang, G. Hu, and H. Zhang, “A wearable heart rate belt for ambulant ECG monitoring," 2012 IEEE 14th Int. Conf. e-Health Networking, Appl. Serv. Heal. 2012, pp. 371-374, 2012.

[12] R. Gayathri and S. K. Vasudevan, "Internet of things based smart health monitoring of industrial standard motors," Indonesian Journal of Electrical Engineering and Informatics, vol. 6, no. 4, pp. 361-367, 2018.

[13] Horace Dediu, Global smartphone penetration nearing 10\%, 2013.

[14] M. O. Diab, R. A. M. Brome, M. Dichari, and B. Moslem, "The smartphone accessory heart rate monitor," Int. Conf. Comput. Med. Appl. ICCMA 2013, pp. 1-5, 2013.

[15] H. Mansor, S. S. Meskam, N. S. Zamery, N. Q. A. M. Rusli, and R. Akmeliawati, "Portable heart rate measurement for remote health monitoring system," 2015 10th Asian Control Conf. Emerg. Control Tech. a Sustain. World, ASCC 2015, no. June 2013, pp. 1-5, 2015.

[16] P. A. Pawar, "Heart rate monitoring system using IR base sensor \& Arduino Uno," Proc. 2014 Conf. IT Business, Ind. Gov. An Int. Conf. by CSI Big Data, CSIBIG 2014, pp. 1-3, 2014.

[17] R. Miyauchi, K. Tanno, and H. Tamura, "Simple measurement system for biological signal using a smartphone," International Journal of Electrical and Computer Engineering (IJECE), vol. 8, no. 6, p. 4157, 2018.

[18] K. I. Ahmed, M. H. Habaebi, and M. R. Islam, "Smartphone aided real-time blood vein detection system," Bulletin of Electrical Engineering and Informatics, vol. 8, no. 3, pp. 1096-1107, 2019.

[19] N. F. A. Jamal, K. A. Sidek, and A. Z. Jusoh, "Portable health monitoring kit using photolethysmogram signal," Indonesian Journal of Electrical Engineering and Computer Science, vol. 15, no. 2, pp. 638-649, 2019.

[20] T. S. Gunawan et al., "Prototype design of smart home system using internet of things," Indonesian Journal of Electrical Engineering and Computer Science, vol. 7, no. 1, pp. 107-115, 2017.

[21] N. Nowshin, P. Mazumder, M. A. Soikot, M. Probal, and M. U. Qadir, "Designing and implementation of microcontroller based non-invasive health monitoring system," 1st Int. Conf. Robot. Electr. Signal Process. Tech. ICREST 2019, pp. 134-139, 2019.

[22] M. L. Shuwandy, B. B. Zaidan, A. A. Zaidan, and A. S. Albahri, "Sensor-Based mHealth Authentication for RealTime Remote Healthcare Monitoring System: A Multilayer Systematic Review,” J. Med. Syst., vol. 43, no. 2, 2019.

[23] R. S. Rosli, M. H. Habaebi, and M. R. Islam, "Analysis of different digital filters for received signal strength indicator," Bulletin of Electrical Engineering and Informatics, vol. 8, no. 3, pp. 970-977, 2019.

[24] E. G. Zhilyakov, S. P. Belov, I. I. Oleinik, S. L. Babarinov, and D. I. Trubitsyna, "Generalized sub band analysis and signal synthesis,” Bulletin of Electrical Engineering and Informatics, vol. 9, no. 3, pp. 964-972, 2020.

[25] C. F. Soon, et al, "Bluetooth embedded digital ammeter with Android app data logging," Indonesian Journal of Electrical Engineering and Computer Science, vol. 18, no. 3, pp. 1400-1407, 2020.

[26] N. H. Wijaya, F. A. Fauzi, E. T. Helmy, P. T. Nguyen, and R. A. Atmoko, "The Design of Heart Rate Detector and Body Temperature Measurement Device Using,” J. Robot. Control, vol. 1, no. 2, pp. 40-43, 2020.

[27] O. Brodersen, et al, "In-ear acquisition of vital signs discloses new chances for preventive continuous cardiovascular monitoring," IFMBE Proc., vol. 13, no. Figure 1, pp. 189-194, 2007.

[28] R. Roediger, et al., "The revised digital transcutaneous PCO 2/SpO 2 ear sensor is a reliable noninvasive monitoring tool in patients after cardiac surgery," J. Cardiothorac. Vasc. Anesth., vol. 25, no. 2, pp. 243-249, 2011. 
[29] P. A. Gisiger, J. P. Palma, and P. Eberhard, "OxiCarbo®, a single sensor for the non-invasive measurement of arterial oxygen saturation and $\mathrm{CO} 2$ partial pressure at the ear lobe," Sensors Actuators, B Chem., vol. 76, no. 1-3, pp. 527-530, 2001.

[30] M. Pravin Savaridass, N. Ikram, R. Deepika, and R. Aarnika, "Development of smart health monitoring system using Internet of Things," Mater. Today Proc., 2020.

[31] S. Fuada, A. P. Putra, Y. Aska, and T. Adiono, "Noise analysis of trans-impedance amplifier (TIA) in variety op amp for use in visible light communication (VLC) system," International Journal of Electrical and Computer Engineering (IJECE), vol. 8, no. 1, pp. 159-171, 2018.

[32] D. Kofjač, R. Stojanović, A. Koložvari, and A. Škraba, "Designing a low-cost real-time group heart rate monitoring system," Microprocess. Microsyst., vol. 63, pp. 75-84, 2018.

[33] K. Sokolova, C. Perez, and M. Lemercier, "Android application classification and anomaly detection with graphbased permission patterns," Decis. Support Syst., vol. 93, pp. 62-76, 2017.

[34] T. Munasinghe, E. W. Patton, and O. Seneviratne, "IoT application development using MIT app inventor to collect and analyze sensor data," Proc. - 2019 IEEE Int. Conf. Big Data, Big Data 2019, pp. 6157-6159, 2019. 